\title{
THE PREVALENCE AND BURDEN OF MENTAL AND SUBSTANCE USE DISORDERS IN ROMANIA: FINDINGS FROM THE GLOBAL BURDEN OF DISEASE STUDY 2016
}

\author{
Mihai-Bogdan Iovu ${ }^{1}$ \& Maria Alina Breaz ${ }^{2}$ \\ ${ }^{I}$ Social Work Department, Babeş-Bolyai University, Cluj-Napoca, Romania \\ ${ }^{2}$ Pedagogy, Psychology and Social Work Department, Aurel Vlaicu University of Arad, Arad, Romania
}

received: 20.9.2018;

revised: 4.9.2019;

accepted: 18.9.2019

\section{SUMMARY}

Aims: National mental health policies must be grounded in accurate assessments of diseases. In the current article we used the Global Burden of Disease Study 2016 to examine burden due to mental and substance use disorders in Romania.

Methods: For each mental and substance use disorder included in the GBD 2016 we reported the yearly estimates for YLL (as a measure for non-fatal burden), YLD (fatal burden) and DALY (summing years lived with disability and years of life lost to give a measure of total burden).

Results: Mental and substance use disorders were the third leading cause of non-fatal burden in Romania in 2016, explaining $13.53 \%$ of total years lived with disability, the ninth leading cause for fatal burden explaining $0.84 \%$ of total years of life lost, and were the fifth leading cause of total burden, accounting for 5.52\% of total disability-adjusted life years. Among MSDs, depression, anxiety and alcohol use disorders have the highest rate. Starting 1997 there has been a slow decrease of age-standardized disabilityadjusted life year rates, with no significant change in the last 5 years.

Conclusion: Global Burden of Disease Study 2016 found that mental and substance use disorders were the fifth leading contributors to disease burden in Romania, with anxiety and depressive being the most prevalent. Despite national programs and strategies in the area of mental health initiated especially after 1990, the mental health system does not fully meet the needs of the patients. Effective population-level strategic measures are still required in order to reduce the burden of disease.

Key words: global burden of disease - mental disorders - substance use disorders - Romania

$$
* * * * *
$$

\section{INTRODUCTION}

Mental and substance use disorders (MSDs) are considered a major public health concern (WHO 2001), around 1:6 (15-20\%) people worldwide having one or more mental or substance use disorders in 2016. This equals to more than 1.1 billion people, the most prevalent MSDs being anxiety disorders (3.83\%) and depression (3.77\%) (Ritchie \& Roser 2018). Similarly, at regional level, Health at the Glance: Europe 2018 report concludes that mental health problems affect more than one in six people across the European Union in any given year (OECD/EU 2018). Therefore, European Union has recognized mental health among the first priorities of the public health agenda (WHO 2015). Wittchen et al. (2011) estimates a 38.2\% oneyear prevalence of any mental disorder for Europe. Depressive disorder is twice as common in women as in men. About $1-2 \%$ of the population is diagnosed with psychotic disorders, men and women equally, and 5.6\% of men and $1.3 \%$ of women have substance use disorders (WHO 2015). At national level, 1:5 Romanians is affected by mental health problems, and at least 250,000 Romanians suffer from a severe psychiatric disorder (Paziuc \& Paziuc 2017). Compared to the EU rates, the prevalence for mental health disorders is one of the lowest in Romania (less than $15 \%$ of the population having at least one disorder), but this may be due to the fact that there is a great stigma associated with the mental illness and therefore less self-reporting associated with limited access to mental health care services for those who acknowledge the illness (OECD/EU 2018). For 2017, National Institute of Statistics (2019) reports 248,434 discharges of those treated for mental and behavioural disorders, a slight decrease compared to last years, accounting for $6.2 \%$ of total in-patient hospital discharges. Eurostate (2018) shows that this rate is higher than the value for EU countries with available data $(5.6 \%)$.

Mental disorders are also a leading contributor to the global disease burden. In 2016, 6.77\% of global DALYs (Disability-Adjusted Life Years), the fourth cause of non-communicable diseases after cardiovascular, neoplasm and other non-communicable diseases, and 18.73\% of global YLDs (Years Lived with Disability) were due to mental disorders (WHO 2018a). This leads to a financial burden of an estimated 800 billion EUR for mental and neurological disorders taken together. $40 \%$ of this was attributed to indirect costs in terms of individuals' loss of production, $37 \%$ to healthcare costs, and the remaining $23 \%$ to social services costs (Gustavsson et al. 2011). For EU-28 countries the $\mathrm{OECD} / \mathrm{EU}$ report (2018) estimates the total costs of mental ill-health at over EUR 600 billion or an average 
of $4.1 \%$ of GDP in 2015. In 2015, the overall costs of mental health related to mental illness are estimated at $2.12 \%$ of GDP in Romania, equating to EUR 3400 million. This total breaks down into the equivalent of $0.94 \%$ of GDP (or EUR 1,510 million) in direct spending on health system, $0.46 \%$ of GDP (or EUR 737 million) on social security benefits and $0.72 \%$ of GDP (or EUR 1,153 million) in indirect costs related to the labour market (OECD/EU 2018).

But we must not forget that mental illness is associated with such economic consequences, but also the emotional burden on the patients and on their families and communities is an important aspect of their rehabilitation and successful inclusion.

\section{Mental health system in Romania}

In a formal definition, mental health system includes the institutions and the set of activities whose primary purpose is to promote, maintain or restore mental health. However, when analyzing the current mental health system we should include both the structures within the general health system, and also the social services, equally essential for mental health care (Dlouhy 2014). Romania has experienced major transition in the development of the mental health system as a response to mental illness, especially after 1989 and with EU pressure. Therefore, the following section will summarize the current state of mental health system in the country in the areas of: (1) financing, (2) infrastructure, and (3) policy.

\section{Mental health financing}

Mental health is a component of the general health system. Romanian health system is financed from four main sources: national health insurance funds (NHIF), the state budget, local budgets and out-of-pocket payments (OPP), while voluntary health insurances (VHI) are low. Funds from the state budget are used for the implementation of preventive national health programmes and for investments, while local budgets supports the maintenance costs and in-patient meals. OOP payments consist mainly of direct payments for services offered by private health providers and co-payments for certain medicine and other services (Vlădescu et al. 2016)

According to the latest public Eurostat data (2018), Romania continues to spend the lowest amount of all European Union member states on healthcare. In 2015, the total health expenditure (THE) per capita was 400 EUR meaning $5 \%$ of gross domestic product (GDP) compared to EU average of $8.4 \%$. Since 2010, OECD/EU report (2016) notices a continuous decrease of healthcare spending as share of GDP.

Although the total is low, the proportion that is publicly funded is relatively high, ranking Romania the tenth on EU-28, with over $78 \%$ of THE being publicly funded, which is also above the EU-28 average (72.6\%). Most public funding came from the health insurance contributions to the NHIF $-64 \%$ in 2015 . The share of OOP was the second largest source of revenue for healthcare spending $(21.3 \%$ in 2015$)$, while the contribution of VHI continues to be quite marginal $(0.3 \%)$. The share of informal payments is thought to be substantial, but the size is not fully known. The latest Eurbarometer on corruption (2017) concluded that 19\% of Romanians made an extra payment, gave a gift or made a donation on top of the official fees when in contact with the public healthcare system during the previous year. Although there was a small improvement, the rate remained the highest in EU (EU-28 average: $4 \%$ ). While almost all the other countries (except Belgium, Bulgaria, and Latvia) spend more than $50 \%$ on curative and rehabilitative care services, Romania recorded the lowest value of $42.9 \%$. By contrast, the other major category of spending is medical goods for which it ranks the second after Bulgaria with 39.6\%. Expenditure related to preventive care exhibited less variation within member states, but Romania $(2.1 \%)$ is placed below the EU average of $2.6 \%$. Hospitals generally accounted for the highest proportion of current healthcare expenditure in 2015 (39.1\%).

As for specific financing of the mental health within the general health financing, in the EU, the mean value of mental health expenditure as a share of total health expenditure was estimated at $6.8 \%$ (Jacob et al. 2007). The estimate for Romania was 3\%, a little higher than Bulgaria (2.5\%), but a lot less than Hungary (8\%) compared to neighboring EU member states. Therefore, we may conclude that mental health is relatively underfinanced in comparison to other health components. Dlouhy (2014) also concludes that the low financing level is a serious problem as in general, the countries of Eastern Europe spend a lower share of the GDP on total health expenditure, and from this small amount they spend a lower share of the total health expenditure on mental health services. How this impacts the Romanian mental health system is noticed in the current mental health infrastructure.

\section{Mental health infrastructure}

The physical infrastructure shows that in Romania in 2017 there were 576 hospitals, almost two thirds of which were public (367). While the number of public hospitals has fallen starting 2010, the number of private hospitals has seen the opposite trend, with a raise of $170 \%$ compared to 2010 . The number of total beds in 2016 was 132,277 a small raise compared to 2010 , but keeping the decreasing trend compared to 1990 (National Institute of Statistics, 2018). Mental health in-patient services in Romania are delivered in long-term care facilities, psychiatric hospitals and psychiatric units in general hospitals. We noticed 77 acute psychiatric departments in general hospitals, 35 acute and chronic psychiatric hospitals (WHO 2015a), 80 community mental health centers (National Institute of Statistics 2018) and day-care centers. Between 2010 and 2015 the 
number of psychiatric care beds in hospitals, relative to the size of population fell in most EU member states, but Romania recorded quite a fast growth from 78.4 to $84.7 / 100,000$, while the EU rate also decreased from was 73.4 to $72.0 / 100,000$. The average length of hospital stays for in-patients treated for mental and behavioural disorders remained constant between in 2010 and 2015 with 17.7 days, compared to EU average of 24.3 days. Generally, in-patients with schizophrenia, schizotypal and delusional disorders and with dementia and Alzheimer's disease spent the highest average number of days in hospital, whereas those with disorders related to the use of alcohol or psychoactive substances generally spent less time in hospital in 2015 (Eurostat 2018).

Human resource infrastructure shows that while there were between 7.6 and 23.6 psychiatrists per 100,000 inhabitants across those EU member states for which data were available, Romania recorded the forth lowest rate, 10.6 (Eurostat 2018). Beside psychiatrists, the number of social workers and psychologists is under dimensioned compared to the needs. All these lead to a HAQ (Healthcare Access and Quality) Index of 78.32 for 2016, a significant improvement compared to last years, but the second lowest from EU after Bulgaria (77.16).

\section{Mental health policy}

Development of Romanian mental health policies has benefited a lot from the EU membership, because mental health has been an important chapter of negotiations during the accession process (Dolhouy 2014). The Mental Health law (no. 487), aiming at improving the social and legal position of persons with mental disorders as well as the quality of and access to mental healthcare facilities, was passed in 2002 and last amended in 2012 followed by rules of implementation, in 2016. The National Mental Health Programme has two components, one for psychiatric and psycho-social pathology and another for prevention and treatment of drug dependence, delivered in psychiatric hospitals and psychiatric departments of the General Hospitals and Mental Health Centres. The National Health Strategy 2014-2020 approved by Government in November 2014 includes a specific strategic objective, ,improving the mental health of population" and a series of actions to be taken during the implementation period: developing prevention programs for mental illness, accurate diagnosis and treatment for psychiatric disorders at community level, improving the capacity of the health system to offer accessible and quality services, and integrating persons with mental disorders in the society through inter-sectorial collaboration. A key aspect is the adoption in November 2016 of the National Strategy for Mental Health for Children and Adolescents 2016-2020 aiming at early identification of children and youth at risk of developing mental health disorders, prevention of mental illness, developing specialized interventions and complex services.
The Annual report analyzing the progress of member states within the European Framework for Action on Mental Health and Wellbeing acknowledges all these important steps taken towards updating and improving the national mental health legislation, but draws attention upon the barriers that significantly impacted the full implementation of the provisions: inadequate/insufficient funding, problems with joint budgeting, lack of available tools, and low political support (Caldas de Almeida et al. 2018). This is not a new issue, as Romanian general healthcare system just manages to respond to a little extent to current needs and expectations of the population, while facing many managerial, structural and financial problems (Popescu 2015).

In conclusion, there are several key-issues facing mental health and social care services in Romania:

- a lack of qualified personnel such as psychiatrists, nurses, psychologists, social workers;

- poor infrastructure and physical conditions;

- lack training of staff working with people with mental health problems;

- attitudes of professionals and staff towards people with mental health problems;

- human rights abuses, disempowerment of people with mental health problems;

- inadequate and/or lack of implementation of existing legislation, including UN CRPD implementation (Mental Health Europe 2017).

\section{METHODS}

GBD 2016 measured burden in terms of disabilityadjusted life years (DALYs), years lived with disability (YLDs), and years of life lost (YLLs) due to premature mortality. Global burden was estimated for 183 countries, age group of 20 years, both sexes and at 5-year intervals beginning in 1990 . Corresponding $95 \%$ uncertainty intervals (UIs), a composite measure to compound uncertainty at different stages of the analysis, were calculated for all the estimates. The methodology has been previously described in other studies (Vos et al. 2016; Wang et al. 2016), but also explained in WHO's technical paper (WHO 2018a). Therefore, using the latest available data on these estimates, this study analyses the relative contributions of different MSDs to total burden and explore variations by age and sex for Romania in 2016 (IHME 2017).

The MSDs included in GBD 2016 and used in study are grouped in 12 categories: depressive disorders (major depressive disorder, dysthymia), bipolar disorder, schizophrenia, alcohol use disorders, drug use disorders (opioid, amphetamine, cocaine, cannabis, and other drug dependence), anxiety disorders, eating disorders, autism spectrum disorders (ASDs), childhood behavioral disorders (attention-deficit/hyperactivity disorder (ADHD) and conduct disorder), idiopathic developmental intellectual disability (a residual category capturing intellectual disability not attributable to any other cause) and a residual group of other MSDs. 
Non-fatal burden was measured in YLDs where one YLD equates to one year lived in less than ideal health. YLDs were calculated by multiplying the prevalence of a disorder by a disorder-specific disability weight (Vos et al. 2016). The YLLs for a cause are essentially calculated as the number of cause-specific deaths multiplied by a loss function specifying the years lost for deaths as a function of the age at which death occurs (WHO 2018a). The DALY estimate is an aggregate measure which combines time lost through premature death and time lived in states of less than optimal health, generally referred to as "disability", generated by summing YLDs and YLLs for each disorder. One DALY equates to one lost year of healthy life (WHO 2018a).

\section{RESULTS}

\section{Prevalence}

Figure 1 shows the prevalent cases of analyzed MSDs in Romania in 2016. Anxiety and depressive disorders were the most prevalent, followed by other MSDs and substance use disorders. This is similar to other Romanian studies, Florescu et al. (2009) showing anxiety $(4.9 \%)$ and mood disorders $(2.3 \%)$ as the most prevalent 12 months disorders. Depressive disorder has become one of the most frequent disorders in Romania with a higher prevalence for women and at older age (Patriche et al. 2015). In our study as well, females had higher prevalence rate of anxiety disorders (4,553.0 prevalent cases per 100,000 of the population, $95 \%$ UI: $4,102.2$ $5,031.8)$, depressive disorders $(3,650.8$ prevalent cases per 100,000, 95\% UI: 3,337.9-3,963.0), and bipolar disorders (839.1 prevalent cases per 100,000, 95\% UI: 735.9-958.6) than males, while males showed higher prevalence of alcohol use disorders (2036.3 per 100,000, 95\% UI: 1,792.8-2297.2), autistic spectrum disorders (1,283.9 per $100,000,95 \%$ UI: $1,119.3-1,487.2)$, ADHD (841.4 per $100,000,95 \%$ UI: $757.4-940.7)$ and conduct disorders (627.1 per 100,000, 95\% UI: 527.6-736.8) than females. WHO study (2018) also reports a 3 times higher prevalence rate for males for alcohol use disorders.

\section{Non-fatal burden}

MSDs were the third leading cause of YLDs in Romania in 2016, accounting for 353,485 YLDs (95\% UI: $258,009-454850)$ or $13.53 \%$ (95\% UI: $11.4-15.2 \%)$ of all YLDs, a small raise compared to 2015, whereas starting from 1990 there has been a slow, but steady decrease. This equated a rate of 1,825.4 MSD YLDs per 100,000 of the population (95\% UI: 1332.8-2348.9). Depression (3.75\%) and anxiety disorders (2.52\%) recorded the highest percentage of all YLDs.

\section{Fatal burden}

In 2016, MSDs were responsible for 37,569 YLLs (95\% UI: 33,019-42,848) in Romania, making them the ninth leading cause of non-communicable diseases (constant since 1998) of YLLs and explaining 0.84\% (95\% UI: $0.7-0.9 \%$ ) of all YLLs in Romania. The rate of MSD YLLs decreased between 1997 (438.9 YLLs per 100,000, 95\% UI: 404.1-480.1) and 2015 (186.8 YLLs per 100,000, 95\% UI: 169.7-204.7), with a small increase in the last year (194 YLLs per 100,000, 95\% UI: 170.5-221.2), this being driven by alcohol and drug use disorders.

\section{Total burden}

In 2016, MSDs were the fifth leading cause of DALYs in Romania after cardiovascular diseases, neoplasms, musculoskeletal disorders, and other non-communicable diseases. They contributed 391,054.4 DALYs (95\% UI: $296,114.9-493,710.3)$, equating to $5.52 \%$ (95\% UI: $4.5-6.4 \%$ ) of all DALYs in Romania and a rate of 2,019.4 DALYs per 100,000 (95\% UI: 1,529.22,549.6). This rate did not significantly changed during

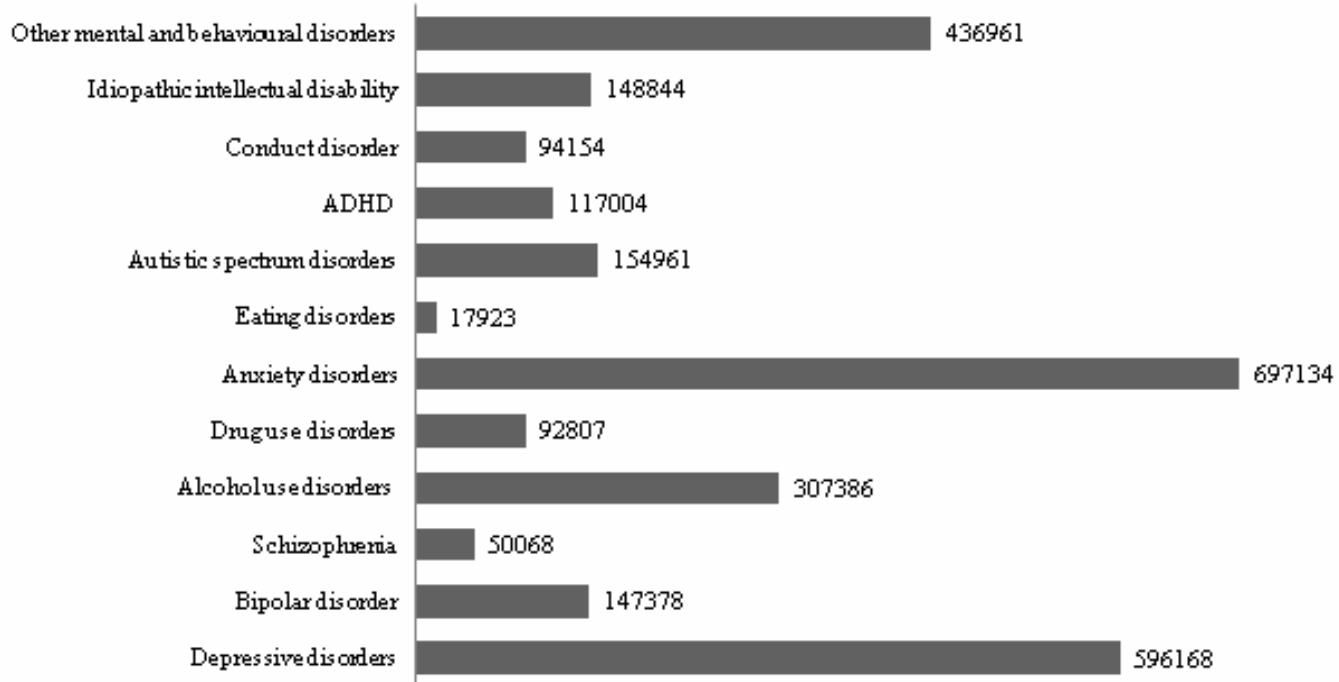

Figure 1. Prevalent cases 


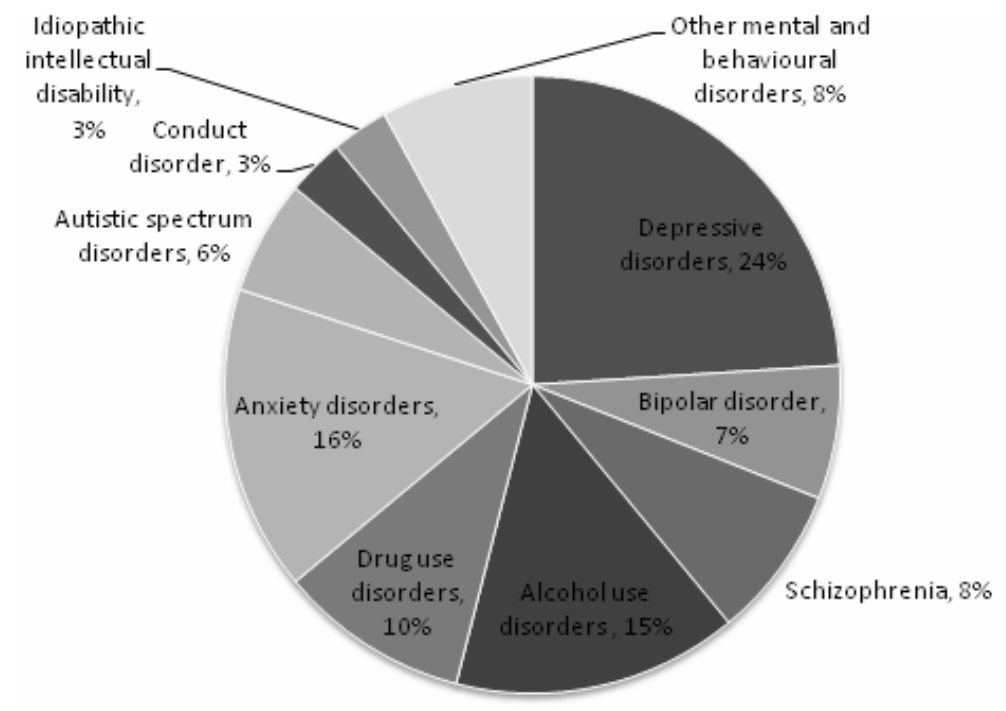

Figure 2. Substance use disorders

Table 1. The rate of DALYs by disorder for males and females in Romania in 2016

\begin{tabular}{lccc}
\hline MSD & Total & Males & Females \\
\hline Depressive disorders & $506.3(349.9-680.3)$ & $409.6(278.8-555.8)$ & $597(414-806.3)$ \\
Anxiety disorders & $340.5(238.5-460.5)$ & $246.1(172.3-334)$ & $429.2(298.7-578.7)$ \\
Alcohol use disorders & $262.9(209.9-322.8)$ & $382.7(310.9-462.3)$ & $150.5(113.4-196.8)$ \\
Drug use disorders & $189.1(156.8-222.9)$ & $239.7(197.4-284.1)$ & $141.7(114.8-171.9)$ \\
Other MSDs & $165(115.3-235.1)$ & $189.8(131.5-270.2)$ & $141.7(98.8-201.7)$ \\
Schizophrenia & $163.6(117.7-211.4)$ & $168.5(120.8-220.6)$ & $158.9(113.9-205.7)$ \\
Bipolar disorder & $153.5(95.7-224.1)$ & $137.1(84.5-201.8)$ & $168.8(106.1-250.3)$ \\
Autism spectrum dis. & $118.7(80-166.6)$ & $183.7(123.3-256.9)$ & $57.6(38.7-83.1)$ \\
Conduct disorder & $59.2(36.2-90.3)$ & $76.5(47.1-115.9)$ & $42.9(25.7-67.2)$ \\
Idiopathic developmental intellectual disability & $34.3(14.6-60)$ & $38.8(17.0-68.1)$ & $30.1(12.9-53.9)$ \\
Eating disorders & $18.7(11.7-27.4)$ & $10(6-15.5)$ & $27(16.7-38.8)$ \\
ADHD & $7.27(4.3-11.5)$ & $10.1(5.9-16.3)$ & $4.5(2.7-7.2)$ \\
\hline
\end{tabular}

Note: $95 \%$ UIs are shown in brackets. Disorders are ordered as per highest to lowest total DALY rates

the last 5 years, the highest being recorded in 1997 (2,263 DALYs per 100,000, 95\% UI: 1,745.3-2,820.2), the moment when it first started to decrease. If controlled for variations in the age structure of the population, the age standardized rate of MSDs in Romania in 2016 (1,837.3 DALYs per 100,000, 95\% UI: $1,386.1-$ $2,327.4)$ is the smallest compared to global mean $(2,183.3$ per 100,000, 95\% UI: 1,627.1-2,766.3), European Union mean $(2,371.8$ per $100,000,95 \%$ UI: $1,769.5-3,022.6)$ or Central Europe $(1,932.7$ per $100,000,95 \%$ UI: $1,466.3$ 2,450.6). Among the neighboring countries (Bulgaria, Serbia, Hungary, Ukraine and Moldova), only Bulgaria (1,790.9 per $100,000,95 \%$ UI: $1,320.1-2,302.4)$ had a smaller rate, the highest rates being recorded for Moldova $(2,528.7$ per $100,000,95 \%$ UI: $1,966.1-3,139.6)$ and Ukraine (3,074 per 100,000, 95\% UI: 2,390.8-3,870.6).

Within MSDs in Romania, substance use disorders (drugs and alcohol) were responsible for $25 \%$ and depressive disorders, bipolar disorder, and anxiety disorders were responsible for almost $50 \%$ of all DALYs due to MSDs as shown in Figure 2.

Depressive disorders were ranked the $15^{\text {th }}$ leading cause of all burden for non-communicable diseases in
Romania in 2016 (1.38\%, 95\% UI: $1-1.7 \%)$ and alcohol use disorders the $29^{\text {th }}$ leading cause, due to its general low prevalence $(0.72 \%, 95 \%$ UI: $0.6-0.8 \%)$.

The overall DALY rate of MSDs in Romania in 2016 was higher in males $(2,093,95 \%$ UI: $1,616.9-$ 2,609.6) compared to females (1,950.4, 95\% UI: $1,439.8$ - 2,478.7). Males experienced higher DALY rates of drug use disorders, alcohol use disorders, schizophrenia, conduct disorders, ADHD, and ASDs compared to females, while females had higher DALY rates for depressive disorders, anxiety disorders, bipolar disorder, and eating disorders than males (Table 1).

Figure 3 shows DALY rates in 2016 for each disorder by age in Romania. Burden due to MSDs was present across the lifespan, peaking during adulthood and then declining with age. Depressive and anxiety disorders had the highest rates of burden in most age groups, while conduct disorder, ASDs and anxiety disorders contributed the majority of MSD burden during childhood. Alcohol use disorder, eating disorders, and schizophrenia reach their peak of burden during adulthood, while depressive disorders reach their peak during 75-79 age group. 


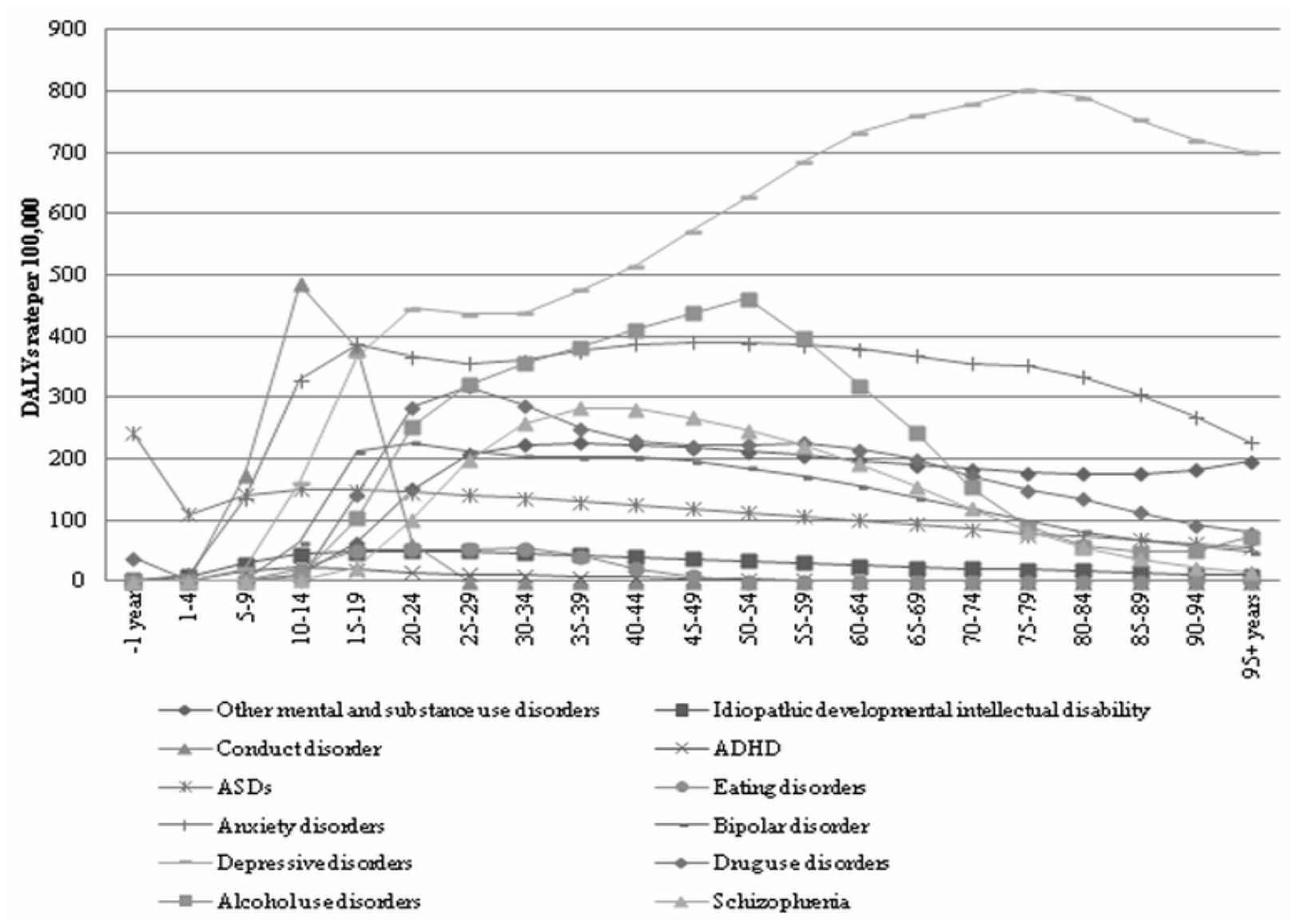

Figure 3. DALY rates in 2016

\section{DISCUSSION}

GBD 2016 found that MSDs remain in the first three leading causes of YLDs and the sixth leading cause of DALYs in Romania, while there has been no significant change in DALY rates between 1993 and 2016. The only significant trend over time was an increase in YLLs due to drug use disorders. These findings indicate that the increased attention MSDs have gained at policy level and in research has not been fully translated into a significant decrease in burden. This could be explained by the fact that the national programs and strategies are during their implementation period and the full impact will be noticed at the end. So we might say that it is quite premature to state that initiatives on mental health in Romania are not effective. Multiple structural actors need to become more involved in this monitoring process. Due to the lack of nationally epidemiological studies in Romania, very little is known about the general population prevalence or severity of mental disorders (Florescu 2009). Therefore, Ministry of Health needs to promote and sustain further studies on the epidemiology of mental disorders both at regional and national level. Government should provide constant incentives to hospitals to expand and improve their mental health facilities or create new ones in order to meet future demands of the community. Ministry of Education through the medical, psychology and social work schools should motivate students to specialize in mental health training to ensure the necessary number of professionals with an adequate level of expertise. Ministry of Work should create programs to sustain professionals to provide constant mental health services, especially in rural areas.

But probably the most important support must be in reorientation of mental health services from institutional- to community-based services. The need of urgent policy measures is also highlighted by the 2016 Social Justice Index which with a score of 3.76 in health dimension, places Romania second to last in the EU (Schraad-Tischler \& Schille 2016). The National Health Strategy 2014-2020 as the guiding document of health care reforms established the creation of integrated community health centres as a way to reduce inequalities in access to health care, education and other social services (Ministry of Health, 2014). However, there is little evidence about the impacts of changes introduced to enhance mental health care services on population health indicators (Vlădescu et al. 2016). For example, it took 3 years for the Government to approve (May 2019) the methodological norms for the organization, functioning and financing of medical community care set in the National Strategy, providing financing only for 1,556 community care nurses and 470 health mediators (especially for Roma communities). In general, we may conclude that even if the Government set a list of national priorities for mental health care, their provision is not yet enforced and the policy in mental health is perceived 
as being fragmented and discontinued because the implementation is dependent on the political will as well. For example, since 1989, almost 30 ministers of health have stopped and initiated new policies when they were appointed.

Although Global Burden of Disease is the most comprehensive collaborative network in assessment of disease burden to date, there are some limitations to be considered when looking at the findings. GBD looks at disability in terms of health loss and does not consider the impact of MSDs on later outcomes, families, or society as a whole (Wang et al. 2016). Furthermore, in GBD, suicide is categorized under injuries rather than MSDs. As such, the YLL component does not reflect the significantly increased risk of premature mortality in people with mental disorders (Chesney et al. 2014).

\section{CONCLUSIONS}

This paper aimed to examine the burden due to mental and substance use disorders in Romania after several years of mental health reforms, using a macroscopic perspective provided by Global Burden of Disease study 2016. Our analysis showed that MSDs remained important contributors to the total burden of disease in Romania. Moreover, due to the current socio-economic context, the relative burden of disease of MSD is expected to accelerate in the near future.

As a subsidiary goal, we intended to raise an urgent signal of alarm to national public health policy-makers. These results ought to lead to improved mental health care if policy-makers use them to develop sustainable health care policies to meet the needs of population. The mental health sector needs to develop more efficacious interventions and pay an increased attention to prevention if the burden of MSDs is to be reduced. This it will require more efficacious responses from the State in the area of financing, developing human resource, and specific preventive mental health care policies.

\section{Acknowledgements:}

Availability of Data and Materials:

All the computations are made using the available data from Institute for Health Metrics and Evaluation (IHME). GBD Compare Data Visualization. Seattle, WA: IHME, University of Washington, 2017. Available from http://vizhub.healthdata.org/gbd-compare.

\section{Conflict of interest: None to declare.}

\section{Contribution of individual authors:}

Mihai-Bogdan lovu conceived the study, performed the analysis and took the lead in writing the manuscript,

Alina Maria Breaz contributed to the interpretation of the results and reviewed the manuscript.

Both authors provided critical feedback and helped shape the research, analysis and final manuscript.

\section{References}

1. Caldas de Almeida JM, Frasquilho D, Zózimo J, Petrea I, Steenhuis C, Parkkonen J: EU Compass for action on mental health and wellbeing. Annual activity reports of member states and stakeholders. 2018. Available at https://ec.europa.eu/health/sites/health/files/mental health /docs/2018_compass_activityreport_en.pdf. Accessed on 20 June 2018

2. Chesney E, Goodwin GM, Fazel S: Risks of all-cause and suicide mortality in mental disorders: A meta-review. World Psychiatry 2014; 13:153-160

3. Dlouhy M: Mental health policy in Eastern Europe: a comparative analysis of seven mental health systems. BMC Health Services Research 2014; 14:1-8

4. Eurobarometer: Special Eurbarometer 470: Corruption. Directorate-General for Migration and Home Affairs (DG HOME), 2017

5. Eurostat: Mental health and related issues statistics. 2017. Available at http://ec.europa.eu/eurostat/statisticsexplained/index.php/Mental_health_and_related_issues_st atistics. Accessed on 20 June 2018

6. Florescu S, Ciutan M, Popovici G, G?l?on M, Ladea M, Pethukova $M$ et al: The Romanian mental health study: main aspects of lifetime prevalence and service use of DSM IV disorders. Management in Mental Health 2009; $13: 22-30$

7. Gustavsson A, Svensson M, Jacobi F, Allgulander $C$, Alonso J, Beghi E, et al.: Cost of disorders of the brain in Europe 2010. Eur Neuropsychopharmacol 2011; 21:718-79

8. Institute for Health Metrics and Evaluation (IHME): GBD Compare Data Visualization. IHME, University of $\mathrm{Wa}$ shington: Seattle, WA. 2017. Available at http://vizhub. healthdata.org/gbd-compare. Accessed on 10 June 2018

9. Jacob KS, Sharan P, Mirza I, Garrido-Cumbrera M, Seedat $S$, Sreenivas $V$ et al.: Mental health system in countries: where are we now? Lancet 2007; 370:1061-1077

10. Mental Health Europe: Mapping and understanding exclusion: institutional, coercive and community-based services and practices across Europe. Brussels. 2017. Available at https://doi.org/10.22024/UniKent/01.02/64970. Accessed on 2 September 2019

11. Ministry of Health: National Health Strategy 2014-2020. Ministry of Health: Bucharest. 2014. Available at http://www.ms.ro/documente/Anexa\%201\%20-

$\% 20$ Strategia\%20Nationala\%20de\%20Sanatate_886_176 1.pdf. Accessed on August 292019

12. National Institute of Statistics: Latest updates on Tempo online database. INS. Bucharest, 2019. Available at http://statistici.insse.ro:8077/tempo-online/\#/pages/tables/ insse-table. Accessed on 10 August 2019

13. OECD/EU: Health at a Glance: Europe 2016 - State of Health in the EU Cycle. OECD Publishing. Paris, 2016. Available at http://dx.doi.org/10.1787/9789264265592-en. Accessed on 15 August 2018

14. OECD/EU: Health at a Glance: Europe 2018 - State of Health in the EU Cycle. OECD Publishing. Paris, 2018. Available at https://doi.org/10.1787/health_glance_eur2018-en. Accessed on 2 September 2019

15. Patriche, D, Filip, I, T?nase, C: Epidemiology of depression. Revista Medical? Român? 2015; 62:260-62

16. Paziuc A \& Paziuc L: Rethinking mental health in Romania - the role of social psychiatry. Psihiatru.ro 2017; 49. DOI: 10.26416/Psih.49.2.2017.1100 
17. Popescu L: Analysis of National Health Strategy 20142020. Theoretical and Applied Economics 2015; 4:177-88

18. Ritchie H \& Roser M: Mental Health. Published online at OurWorldInData.org. 2018. Available at

https://ourworldindata.org/mental-health. Accessed on 17 July 2018

19. Schraad-Tischler D \& Schille C: Social Justice in the EU - Index Report 2016. Social Inclusion Monitor Europe, Bertelsmann Stiftung. 2016. Available at https://www.bertelsmann-stiftung.de/fileadmin/files/BSt/ Publikationen/GrauePublikationen/Studie_NW_SocialJustice-Index_2016.pdf. Accessed on 31 August 2019

20. Van Oss J: Mental disorder: a public health problem stuck in an individual-level brain disease perspective? World Psychiatry 2015; 14:47-48

21. Vladescu C, Scîntee SG, Olsavszky V, Hernández-Quevedo $C$, Sagan A: Romania: Health system review. Health Systems in Transition 2016; 18:1-170

22. Vos T, Allen C, Arora M, Barber RM, Bhutta ZA, Brown A et al.: Global, regional, and national incidence, prevalence, and years lived with disability for 310 diseases and injuries, 1990-2015: A systematic analysis for the Global Burden of Disease Study 2015. The Lancet 2016; 388:1545-602

23. Wang H, Naghavi M, Allen C, Barber RM, Bhutta ZA, Carter $A$ et al.: Global, regional, and national life expectancy, all-cause mortality, and cause-specific mortality for 249 causes of death, 1980-2015: A systematic analysis for the Global Burden of Disease Study 2015. The Lancet 2016; 388:1459-544

24. Whiteford HA, Degenhardt L, Rehm J, Baxter, AJ, Ferrari AJ, Erskine HE et al.: Global burden of disease attributable to mental and substance use disorders: Findings from the Global Burden of Disease Study 2010. The Lancet 2013; 382:1575-586

25. Wittchen HU, Jacobi F, Rehm J, Gustavsson A, Svensson $M$, Jönsson $B$ et al:: The size and burden of mental disorders and other disorders of the brain in Europe 2010. Eur Neuropsychopharmacol 2011; 21:655-79

26. World Health Organization (WHO): Global status report on alcohol and health 2018. WHO: Geneva, 2018

27. World Health Organization (WHO): Mental Health Atlas 2014. Country profile: Romania. WHO: Geneva, 2015 a

28. World Health Organization (WHO): Mental health: new understanding, new hope. The World Heath Report 2001. WHO: Geneva, 2001

29. World Health Organization (WHO): The European Mental Health Action Plan 2013-2020. WHO Regional Office for Europe: Copenhagen, 2015

30. World Health Organization (WHO): WHO methods and data sources for global burden of disease estimates 2000-2016. Global Health Estimates Technical Paper WHO/HIS/IER/GHE/2018.4. WHO: Geneva, $2018 a$

Correspondence:

Mihai-Bogdan Iovu, PhD

Social Work Department, Babeş-Bolyai University

128, 21 decembrie 1989 Blvd., 400604 Cluj-Napoca, Romania

E-mail:iovu.mihai@ubbcluj.ro 